\title{
Manifestações da cultura afrodiaspórica: um diálogo entre o tempo e os processos de transmissão de saberes
}

Flavia Pimentel Lopes Futata

1 Cientista social com mestrado em educação pela Faculdade de Educação da Universidade de São Paulo (USP) e pós-graduação em gestão cultural contemporânea pelo Instituto Singularidades/Itaú Cultural. E-mail: flavia.tenchi@gmail.com. 


\section{RESUMO}

Este artigo pretende questionar a ideia de que as manifestações da cultura popular de matriz africana, constitutivas de nosso patrimônio cultural junto com as celebrações e rituais ameríndios, são mantenedoras de uma tradição longínqua e celebram uma ancestralidade apartada do corpo e localizada no passado. A partir da noção de tempo espiralar, que se expressa em diversos elementos estéticos destas manifestações, retoma-se alguns dos princípios constitutivos de uma cosmovisão africana especificamente bantu - relacionados ao modo como percebem a ancestralidade e a passagem do tempo. Faz-se ainda uma crítica à ideia de que as escolas e demais espaços institucionais de educação são os lugares privilegiados de transmissão de conhecimento em detrimento das comunidades tradicionais da cultura afrodiaspórica.

Palavras-chave: Tempo espiralar. Manifestações da cultura popular. Ancestralidade.

\section{ABSTRACT}

This article aims to question the idea that manifestations of Afro-American popular culture - which, along with Amerindian celebrations and rituals, constitute our cultural heritage - preserve a remote tradition and celebrate an ancestry separated from the body and located in the past. From the notion of spiraling time, expressed in several aesthetic elements of these manifestations, the text resumes some constitutive principles of an African worldview, specifically that of Bantu, related to how they perceive ancestry and the passage of time. It also criticizes the idea that schools and other educational institutions are privileged places for the transmission of knowledge to the detriment of traditional aphrodiasporic communities.

Keywords: Spiraling time. Manifestations of popular culture. Ancestry. 


\section{INTRODUÇÃo}

Antes de entrar, peço licença a Leda Maria Martins para propor mais uma volta - um voleio - a partir de seu pensamento, deslocando para o território da educação a análise que a autora faz, a partir dos congados mineiros, do tempo experienciado nas manifestações da cultura popular da afrodiáspora (MARTINS, 2002). A intenção aqui não é separar estes territórios: o da educação e o da cultura. É justamente a partir da crítica à ideia de que as instituições de ensino são os espaços privilegiados de educação, que lanço o olhar ao campo da cultura, tateando respostas às questões que me ocupam como educadora envolvida nos processos de transmissão de saberes. O que nos ensinam as manifestações culturais de matriz africana que se repetem no tempo guardando nossas tradições? Antes ainda: repetem-se?

Acompanhando o salto que Martins dá com o conceito-imagem de tempo espiralar, este artigo pretende dialogar com a ideia de que estas manifestações são meras ilustrações de tradições longínquas e encenam um passado apartado do corpo, este desconhecido das escolas e de uma educação colonizadora e utilitária.

Para isso, identifica, nestas manifestações, uma estética africana que reproduz a experiência cíclica de tempo nos diversos elementos 
que expressam uma visão e percepção de mundo e se inscrevem no corpo dos participantes.

Na sequência, põe em diálogo a noção de tempo espiralar de Leda Maria Martins e um dos princípios da cosmovisão bantu sistematizado por Bunseki Fu-Kiau: o dingo-dingo, processo ininterrupto pelo qual passam todas as mudanças.

Reafirmando a ancestralidade como instância vivida no presente e geradora de outras concepções espaciais, propõe uma leitura sobre este corpo afrodiaspórico que é suporte e brecha de múltiplas existências. E, por fim, desloca a análise deste espaço-tempo espiralar para instigar a morte de uma educação colonial e colonizadora em direção a uma pedagogia de terreiro.

\section{MANIFESTAÇõES DA CULTURA AFRODIASPÓRICA}

Ao dispor no mesmo balaio a capoeira, o congado, o boi, o jongo, o maracatu, o tambor de crioula, o candomblé e tantas outras manifestações da cultura negra, reconheço as diferentes relações que travaram na diáspora com os sistemas simbólicos indígena e europeu, resultando em derivações e sincretismos diversos. Porém, o que quero acompanhar aqui é o movimento das imagens destes sistemas simbólicos quando postas em relação e articuladas em um enredo considerando gestos e sonoridades como imagens também.

Como observa Martins (2002), os símbolos católicos, objetos de devoção dos congados, ganham outra feição na complexidade estética da performance ritual, atravessada pelo ritmo dos tambores, dos cantos e dos corpos durante a dramatização:

Ao retirar a santa das águas, imprimindo-lhe movimento, o negro escravo performa um ato de apropriação e reconfiguração, invertendo, na dicção do sagrado, as posições de poder entre brancos e negros. A linguagem dos tambores, investida de um ethos divino, agencia os cantares e a dança e, de forma oracular, prenunciam uma subversão da ordem social, das hierarquias escravistas e dos saberes 
hegemônicos. Esse deslocamento interfere na sintaxe do texto católico, inseminado agora por uma linguagem alterna que, como um estilo e estilete, grafa-se e pulsa na conjugação do som dos tambores, do canto e da dança, entrelaçados na articulação da fala e da voz de timbres africanos. O próprio fundamento do texto mítico católico é rasurado, nele se introduzindo, como um palimpsesto, as divindades africanas. Assim, a santa do Rosário passa a evocar também, por deslocamento, as grandes mães ctônicas africanas, senhoras das águas, da terra e do ar. (MARTINS, 2002, p. 80)

Assim, ao tratá-las de modo genérico, me atento à estética que manifesta uma cosmovisão africana, tendo no cruzo (e na capacidade de fertilizar o diverso) um dos elementos-poder que compõem esta cosmovisão.

Essa estética circular pode ser percebida no formato dos tambores, caixas, cabaças, pandeirões, maracas e nos cantos circulares que amarram perguntas e respostas em coro. Também na forma de organização dos brincantes ou dos corpos em ritual, estão lá as rodas, os cordões, as giras.

Outro elemento fundante desta cosmovisão é o lugar central que o corpo ocupa nestas manifestações. Corpo celebrado, motor dos festejos, que é tanto suporte de inscrição de saberes quanto criador de significados e conhecimentos; que pare Áfricas imaginárias ao mesmo tempo em que se filia a ela.

Nas culturas predominantemente orais e gestuais, como as africanas e as indígenas, por exemplo, o corpo é por excelência, o lugar da memória, o corpo em performance, o corpo que é performance. Como tal, esse corpo/corpus não apenas repete um hábito, mas também institui, interpreta e revisa o ato reencenado. Daí a importância de ressaltarmos nessas tradições performáticas sua natureza meta- constitutiva, nas quais o fazer não elide 
o ato de reflexão; o conteúdo imbrica-se na forma, a memória grafa-se no corpo, que a registra, transmite e modifica dinamicamente.

O corpo nessas tradições, não é, portanto, apenas a extensão ilustrativa do conhecimento dramaticamente representado e simbolicamente reapresentado por convenções e paradigmas seculares. Ele é, sim, local de um saber em contínuo movimento de recriação, remissão e transformações perenes do corpus cultural. (MARTINS, 2002, p. 8889)

Além disso, essas manifestações de cultura - ou performances rituais, como as denomina Martins (2002) - são sempre comunitárias, desenhando uma ética de sociabilidade circular.

A própria concepção sistêmica de comunidade - em que as partes (humanos e não humanos, animados e inanimados) são indissociadas e fazem parte de um todo - é outro elemento desta cosmovisão, assim como a ancestralidade, não como instância do passado, mas presentificada nos corpos, produzindo sentidos e conhecimento.

Se o cruzo é um dos elementos fundantes desta cosmovisão, o tempo espiralar é o organizador dos diversos elementos que reproduzem - como um fractal cujas partes separadas repetem o formato do todo - as formas circulares de percepção de tempo.

\section{O COSMOGRAMA BAKONGO E O TEMPO ESPIRALAR}

Bunseki Fu-Kiau, ${ }^{2}$ difusor da filosofia bantu, trouxe a público, na sistematização que fez da cosmologia bantu-kongo, o cosmograma

2 Pensador congolês nascido em 1934. Iniciado em três escolas de pensamento tradicional bantu, emigrou para os Estados Unidos, onde realizou uma carreira acadêmica entre a Antropologia, a Biblioteconomia e a Educação. Autor de Cosmologia africana dos bantu-kongo: princípios de vida e vivência e Makuku Matatu: os fundamentos culturais bantu entre os kongo. 
bakongo (dikenga dia kongo) que é uma espécie de representação da rota pela qual todos os processos percorrem, seja a vida humana, as criações, as comunidades, o Sol.

\section{Figura 1 - Cosmograma Bakongo (Dikenga Dia Kongo)}

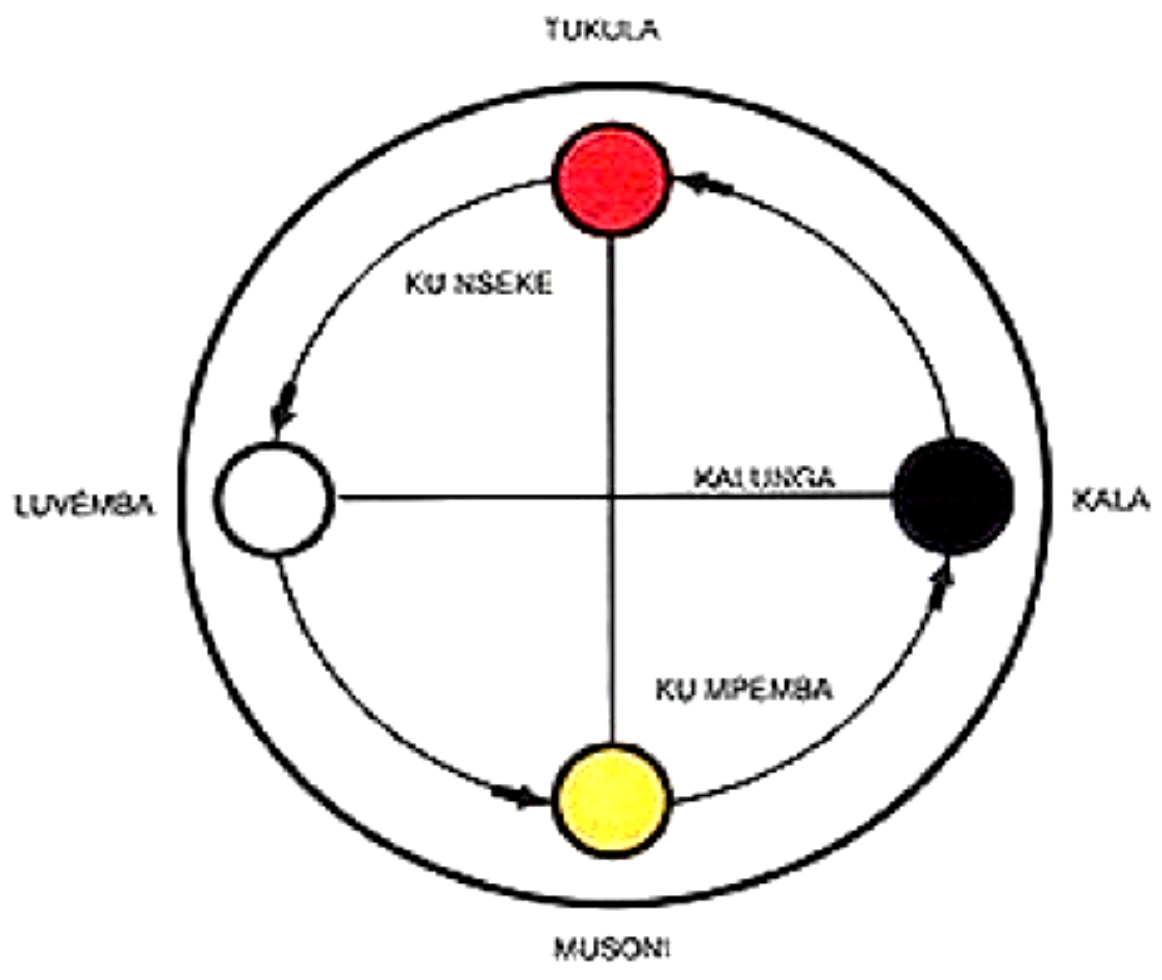

Fonte: https://bit.ly/3ga4i5z.

A linha horizontal que divide o cosmograma em dois é a linha da Kalunga, ${ }^{3}$ formando duas dimensões da existência, dois mundos: o visível (Ku Nseke) e o mundo espiritual (Ku Mpemba), onde habitam os que se ancestralizaram.

Assim, todos os processos existentes implicam a parcela que se mostra e a que, abaixo da Kalunga, é intangível, se desfaz de materialidade e começa a germinar até se apresentar ao mundo,

3 Energia originária, oceano, entre diversas acepções entre os bantu listadas por Santana (2019). 
expressando o princípio bantu dingo-dingo, "[...] o processo, sempre em movimento, de cada 'coisa', para tornar-se, necessariamente, outra 'coisa' [...]" (SANTANA, 2019, p. 130-131).

Para o pensamento bakongo não há descontinuidade de movimento e o intangível, que mora abaixo da linha da Kalunga, é o que permite que tudo desponte em Kala, atinja seu ápice em Tukula e morra em Luvemba, iniciando novo processo em Musoni.

O que reinicia, porém, já não é o mesmo, expresso em Fu-Kiau pela imagem do rolo/bobina que acumula " [...] tesouros biológicos, materiais, intelectuais e espirituais [...]" ao mesmo tempo em que se manifesta como "[...] eterno banco das forças geradoras/motrizes da vida." (FU-KIAU, 2001 apud SANTANA, 2019, p. 56).

Em Martins (2002), isso se expressa pelo conceito-imagem de tempo espiralar, elevando as manifestações culturais afrodiaspóricas à mantenedoras do inédito e afirmando uma cosmovisão africana para dar conta da complexidade exigida pelo mundo contemporâneo:

Esse processo de intervenção no meio e essa potencialidade de reconfiguração formal e conceitual fazem dos rituais um modo eficaz de transmissão e de restituição de uma complexa pletora de conhecimentos. [...] A concepção ancestral africana, inclui, no mesmo circuito fenomenológico, as divindades, a natureza cósmica, a fauna, a flora, os elementos físicos, os mortos, os vivos e os que ainda vão nascer, concebidos como anelos de uma complementaridade necessária, em contínuo processo de transformação e de devir. (MARTINS, 2002, p. 8384)

Assim, essa concepção de ancestralidade manifestada nas performances culturais afrodiaspóricas não cumpre só uma função utilitária de manutenção dos tesouros da humanidade, mas exerce principalmente uma função vivificadora, pela força vital que impulsiona os corpos, e criadora de futuros, pela experiência disruptiva que interfere inclusive na concepção das espacialidades. 


\section{CORPO: ESPAÇO DE MÚLTIPLAS EXISTÊNCIAS}

Viveiros de Castro nos instiga a duvidar do conceito de cultura e, portanto, de humanidade - das diversas tradições antropológicas. Há diferentes sistematizações sobre o que é cultural e o que é natural, e há diferentes leituras sobre o que é humanidade.

Os povos ameríndios rompem com a naturalização de uma ideia de ser humano apartado das demais existências, compreendendo "[...] que nossos corpos estão relacionados com tudo o que é vida, que os ciclos da Terra são também os ciclos dos nossos corpos." (KRENAK, 2020, p. 24).

Consideram, ainda, que há uma intensa comunicação entre os seres as folhas, as divindades, a montanha, o tambor, os ancestrais, o fogo - já que tudo o que existe vibra e pode ser percebido pelos sentidos, aproximando-se muito de um dos fundamentos da cosmovisão bantu: "A vida é fundamentalmente um processo de comunicação constante e mútua, e comunicar-se é emitir e receber ondas e radiações (minika ye minienie)." (FU KIAU, 2021 apud SANTANA, 2019, p. 86).

A restituição de uma cosmovisão que considera esses outros como existências vibráteis e interligadas amplia nossa percepção de nós mesmo, de nosso corpo como encruzilhada de manifestações e de sua potência comunicativa a fim de ampliarmos nosso repertório para o enfrentamento criativo das questões complexas de nossa comunidade maior.

\section{PROCESSOS EDUCATIVOS A PARTIR DE UM IMAGINÁRIO AFRODIASPÓRICO}

[... não é possível fazer uma reflexão sobre o que é educação sem refletir sobre o próprio homem. [...] comecemos por pensar sobre nós mesmos e tratemos de encontrar, na natureza do homem, algo que possa constituir o núcleo fundamental onde se submete o processo de educação. Qual seria este núcleo palpável a partir 
de nossa própria experiência existencial? Este núcleo seria o inacabamento ou a inconclusão do homem. (FREIRE, 1979, p. 27)

Se partirmos, alinhados a Paulo Freire, da condição inacabada do ser humano e da educação como processo contínuo de construção da humanidade nos sujeitos em interação, entendemos que a educação tem um fim em si mesma: tornarmo-nos humanos, coletivamente, denunciando e afastando o que nos desumaniza. Eterno movimento de encontro com o que em nós foi apagado e fragmentado pelo colonialismo para parir as diversas possibilidades existenciais.

Pensar o humano começa por não excluir as formas plurais de existência, as diferentes cosmovisões e as diversas dimensões que nos constituem, inclusive a simbólica, relegada pelo projeto educativo colonizador e eurocêntrico. E pode levar ao encontro de tantas comunidades que se reúnem em torno das produções culturais e religiosas afrodiaspóricas e ameríndias que expressam, em suas éticas e estéticas, cosmovisões que dialogam com o que fomos/somos/seremos.

Tenho direcionado meu olhar para estas comunidades - ora como participante, ora como observadora - atenta à maneira como elas transmitem seus conhecimentos, não a fim de reproduzir, como educadora, essas manifestações de cultura e religiosidade fora de seu contexto original, mas no sentido de reconhecer os processos educativos existentes - e resistentes - nestas comunidades que asseguram por tanto tempo uma ética comunitária da qual estamos tão carentes.

De 2014 a 2018, acompanhei o cotidiano do Quintal da Aldeia, espaço localizado no bairro periférico mais populoso de Pirenópolis/ GO, onde estão os moradores mais antigos, empurrados pelo fenômeno da gentrificação. O espaço é mantido pela ONG Guaimbê, que se entende como articuladora dos projetos comunitários que despontam a partir da convivência entre gerações. 
Participam, cotidianamente, crianças no contraturno escolar, jovens, adultos, até os mais velhos: mestres e mestras respeitados pelo conhecimento que têm do Cerrado - suas plantas, seus remédios, sua história, seus mitos - e das tecnologias comunitárias.

Ali se discutem e realizam projetos artísticos, culturais, de saúde coletiva e educativos enquanto a comunidade o ocupa, consolidando, ao longo dos anos, grupos de práticas, como a Capoeira Angola, e manifestações da cultura popular, como o Boi do Rosário ${ }^{4}$ e a Flor de Pequi, ${ }^{5}$ construindo uma metodologia de educação comunitária nomeada como Pedagogia de Quintal.

O ciclo festivo que marca o nascimento, o batizado e a morte do boi é um mediador do cotidiano já que a comunidade inteira se engaja no preparo das celebrações, o que envolve ensaios, composição de toadas, bordado das roupas dos brincantes e do próprio boi, que, além de vestir um novo couro a cada ano, recebe um novo nome geralmente simbolizando a experiência vivida pela comunidade neste intervalo de tempo.

Percebe-se que a vivência profunda desta manifestação inspira um processo educativo para além dela e que marca todas as outras atividades e projetos culturais, artísticos e de pesquisa nascidos no Quintal da Aldeia. Transmite-se, no convívio comunitário, uma percepção de tempo, de espaço, de ancestralidade que desaguam numa prática educativa que tem como princípios a centralidade do corpo, a oralidade e a convivência intergeracional.

Porém, é no momento dos festejos, cortejos, celebrações que se dá de forma concentrada a experiência disruptiva que atualiza, no corpo, os gestos da tradição. Momentos em que é preciso a comunidade

4 Grupo de Bumba-meu-boi sediado no Ponto de Cultura Quintal da Aldeia e liderado por uma família de origem maranhense e paulista. O Boi do Rosário preserva os elementos musicais do Boi da Baixada (um dos sotaques/estilos encontrados no Maranhão) e o ciclo da festa que marca o seu nascimento, batizado e morte.

5 Coletivo que difunde as brincadeiras e ritos da tradição cultural local. 
inteira para que a Força Vital da ancestralidade se manifeste nos corpos e a experiência produtora de novos sentidos aconteça.

A educação colonial acabou por nos afastar da dimensão do mistério e do sagrado para compreender o ser humano. Tendo apartado o corpo e a dimensão simbólica de suas pedagogias, tornou-se incapaz de transmitir um conhecimento vivo, produtor de novas realidades e sentidos.

A transmissão dos conhecimentos se dá nas encruzilhadas da convivência e a partir de uma educação contínua da sensibilidade para a escuta de outras formas de existir, exercitando outras linguagens e gestos ainda prenhes de sentido.

Mais do que os espaços institucionais de ensino, os terreiros, aldeias, irmandades podem nos lembrar sobre o sentido primeiro da educação a partir do movimento espiralar e incessante, que caracteriza tanto os processos educativos quanto a noção de tempo revelada pela cultura afrodiaspórica. Porque o conhecimento, sempre inacabado, exige plurais revisitas ao que se imaginava capturado, além da sustentação de si em abertura. Exige corpo.

\section{REFERÊNCIAS}

CASTRO, E. V. Perspectivismo e multinaturalismo na América indígena. In: CASTRO, E. V. A inconstância da alma selvagem e outros ensaios de Antropologia. São Paulo: Ubu, 2017. p. 299-346 (Coleção Argonautas).

FERREIRA-SANTOS, M.; ALMEIDA, R. Aproximações ao imaginário: bússola de investigação poética. 2. ed. São Paulo: Feusp, 2020.

FREIRE, P. Educação e mudança. Rio de Janeiro: Paz e Terra, 1979.

FU-KIAU, B. Capoeira e cultura ancestral bantú. In: ENCONTRO INTERNACIONAL DE CAPOEIRA ANGOLA, 3., 1997, Salvador. Anais [...]. Salvador: Fundação Internacional de Capoeira Angola, 1997. Disponível em: https://bit.ly/2VJ2U2S. Acesso em: 27 jun. 2020.

KRENAK, A. A vida não é útil. São Paulo: Companhia das Letras, 2020. KRENAK, A. Ideias para adiar o fim do mundo. São Paulo: Companhia das Letras, 2019. 
MARTINS, L. M. Performances da oralitura: corpo como lugar da memória. Letras, Santa Maria, n. 26, 2003. Disponível em: https://bit. ly/3iCP8aK. Acesso em: 11 ago. 2021.

MARTINS, L. M. Performances do tempo espiralar. In: RAVETTI, G.;

ARBEX, M. (org.). Performance, exílio, fronteiras: errâncias territoriais e textuais. Belo Horizonte: Faculdade de Letras da UFMG, 2002. p. 69-91. Disponível em: https://bit.ly/2U9tgKN. Acesso em: 2 set. 2020.

OLIVEIRA, E. Epistemologia da ancestralidade. Filosofia Africana, [s. l.], 2020. Disponível em: https://bit.ly/37x7iEC.

Acesso em: 23 ago. 2020.

SANTOS, T. S. N. A cosmologia africana dos bantu-kongo por Bunseki Fu-Kiau: tradução negra, reflexões e diálogos a partir do Brasil. 2019. Tese (Doutorado em Letras Modernas) - Faculdade de Filosofia, Letras e Ciências Humanas, Universidade de São Paulo, São Paulo, 2019. 